\title{
Effects of gender in resident evaluations and certifying examination pass rates
}

\author{
Melanie S. Sulistio ${ }^{1,2^{*}}$ D. Amit Khera ${ }^{1,2}$, Kathryn Squiers ${ }^{4}$, Monika Sanghavi ${ }^{1,2}$, Colby R. Ayers ${ }^{2,3}$, Weifeng Weng ${ }^{5}$, \\ Salahuddin Kazi ${ }^{1}$, James de Lemos ${ }^{1,2}$, David H. Johnson ${ }^{1}$ and Lynne Kirk ${ }^{1}$
}

\begin{abstract}
Background: Though the proportion of female Internal Medicine (IM) residents and faculty has increased, there is minimal large scale modern data comparing resident performance by gender. This study sought to examine the effects of resident and faculty gender on resident evaluations.

Methods: Retrospective observational study over 5 years in a single IM program. IM certifying examination pass rates were obtained from the American Board of IM.

Results: Four hundred eighty-eight residents (195 women, 293 men), evaluated by 430 attending physicians (163 women, 270 men) were included. Twelve thousand six hundred eighty-one evaluations between 2007 and 2012 were analyzed. Female residents scored higher in two domains (Medical Interviewing, and Interpersonal and Communication Skills) ( $p<0.01$ for each), with no significant difference between genders for the other domains (Medical Knowledge, Overall Patient Care, Physical Examination, Procedural Skills, Professionalism, Practice Based Learning and Improvement, System Based Practices and Overall score). There were no differences in scoring between female and male attending physicians. There were no differences in certifying examination scores between women and men among graduating residents. National pass rates for women were not statistically different to pass rates for men from 1987 to 2015.

Conclusions: Data from one large academic medical center demonstrate higher ratings for female residents on performance domains reflecting bedside care and interpersonal skills, with similar scores for medical knowledge and remaining domains. No significant difference was seen locally in certifying examination scores, nor in recent national pass rates, an objective measure of medical knowledge. Despite imbalanced female representation in areas of medicine, our data suggest that gender-based disparities in Internal Medicine resident medical knowledge and physician competency are no longer present.
\end{abstract}

Keywords: Gender, Resident evaluations, Certification exam, Medical education

\section{Background}

Historically, significant differences were observed in Internal Medicine (IM) graduate medical education evaluations and in certifying board examination scores according to gender of the resident physician. Program director ratings and evaluation scores were higher for men than women in areas such as medical knowledge, procedural skills and clinical judgment [1,2]. Differences were also described according to attending physician

\footnotetext{
* Correspondence: Melanie.Sulistio@UTSouthwestern.edu

${ }^{1}$ Department of Internal Medicine, University of Texas Southwestern Medical Center, 5323 Harry Hines Blvd, Dallas, TX 75390-8830, USA

2Division of Cardiology, Dallas, USA

Full list of author information is available at the end of the article
}

gender, with male residents rated higher by male attending physicians in several domains [2]. While some contemporary data suggest that gender gaps in evaluation are narrowing [3-5], there continues to be evidence of gender bias [6-9], which may be a key factor in the disparity in female representation beyond residency, specifically in academic leadership $[10,11]$ and in the subspecialties of Cardiovascular disease, Critical Care Medicine and Pulmonary disease, and Gastroenterology [12].

Differences between male and female resident performance on the certifying examination in IM of the American Board of Internal Medicine (ABIM) have also narrowed over time. Previously published reports found

(c) The Author(s). 2019 Open Access This article is distributed under the terms of the Creative Commons Attribution 4.0 International License (http://creativecommons.org/licenses/by/4.0/), which permits unrestricted use, distribution, and reproduction in any medium, provided you give appropriate credit to the original author(s) and the source, provide a link to the Creative Commons license, and indicate if changes were made. The Creative Commons Public Domain Dedication waiver (http://creativecommons.org/publicdomain/zero/1.0/) applies to the data made available in this article, unless otherwise stated. 
between 1973 and 1987, men had higher pass rates than women [1, 13]. But over the period between 1989 and 1992 the gender gap in the ABIM initial certifying examination in Internal Medicine performance appeared to close [14]. However, no further studies have investigated whether this finding persisted or has changed over time.

Further investigation of gender based differences in evaluation of resident performance in the modern era is necessary to monitor for trends and evidence of change, as this may elucidate whether differences in resident performance and medical knowledge influence gender discrepancies beyond residency. Also, performance evaluations have evolved to include the core competencies of the Accreditation Council for Graduate Medical Education (ACGME) [15]. These core competency evaluations provide a more comprehensive assessment of the skills necessary for medical practice. Very few large scale, contemporary studies of the effects of resident and faculty gender on resident performance evaluations have been performed in IM. Thus, as a first step in determining the association of gender on performance assessment in internal medicine and its subspecialties, we aimed to describe contemporary gender-differences in evaluation ratings and ABIM certification examination results using local and national data.

\section{Methods}

Subjects were 488 Internal Medicine residents and 430 faculty at the University of Texas (UT) Southwestern Medical Center between 2007 and 2012. Included residents were enrolled either in a 1 year Internal Medicine preliminary year program, or a 3 year Internal Medicine categorical residency program. Both categorical and preliminary residents were included so that findings regarding gender could be interpreted broadly across both groups. Internal Medicine faculty included those that supervised residents on inpatient clinical rotations. To maintain confidentiality, residents and faculty were assigned unique identifiers. The study was approved by the UT Southwestern Institutional Review Board.

Faculty evaluations of residents were completed using the online New Innovations Inc. (Uniontown, $\mathrm{OH}$ ) platform, and maintained in a secure and confidential database. Outpatient, elective and Clinical Evaluation Exercise evaluations were removed due to differences in reporting structure from the standard inpatient evaluation. Inpatient evaluations were also used because they were the majority of the total evaluations per learner. The evaluation consisted of 9 questions from 6 domains, plus an overall rating score. The domains were defined as the ACGME Core Competencies and included Patient Care, Medical Knowledge, Practice Based Learning and Improvement (PBL), Interpersonal and Communication Skills, Professionalism and System Based Practice (SBP)
[15] (see Additional file 1). Each domain received a single score except Patient Care, which was categorized into four subdomains, including Overall Patient Care, Medical Interviewing, Physical Examination, and Procedural Skills. Each category was measured via a Likert scale from 1 to 9 with an additional option of "No Interaction."

First attempt scores from the ABIM initial certifying examination in Internal Medicine were obtained for residents who completed the 3 year IM Residency program. Residents who were enrolled in the 1 year IM preliminary program were excluded from analyses of examination scores.

Pass rates on the ABIM certifying examination for first time takers were examined from 1972 to 2015, and compared between men and women using Chi-square tests. 1972 was chosen as the initial year for analysis because this year demarcated the elimination of the oral portion of the examination.

\section{Statistical analysis}

Mean scores (+/- standard deviation) for each domain and each resident were determined by averaging scores across all years of data available. Unpaired two-sample Student's $\mathrm{t}$-test was used to compare difference in evaluation scores across the domains for male versus female residents and male versus female faculty. Summary statistics for the equated score for female and male residents were determined by calculating the median and interquartile ranges. Significance was assessed via the Wilcoxon Rank-Sum test. Spearman rank correlation coefficients were calculated to determine the relationship between each resident's average domain score with their equated score on the ABIM certifying examination. Because of the inherent yearly variation in the examination, the scores were equated based on item response theory. To account for multiple comparisons, a significance level of alpha $=0.01$ was used. All analyses were performed using SAS software, version 9.4 (SAS Institute, Cary, NC, USA).

\section{Results}

A total of 488 residents were included, $40 \%$ of whom were women. The number of faculty who completed evaluations was 430 , of whom $38 \%$ were women. The total number of evaluations were 16,623 . Three thousand nine hundred forty-two outpatient, elective and Clinical Evaluation Exercise evaluations were excluded from this total leaving 12,681 remaining to be analyzed. Of the residents included, 355 completed the categorical IM program and received a score for the initial ABIM certifying examination in IM.

Women and men received similar overall summary scores $(7.27$ vs $7.19, p=0.12)$. Differences in ratings by gender were observed for Medical Interviewing and 
Interpersonal and Communication Skills where women were rated higher than men (Table 1). There was borderline significance in Overall Patient Care $(p=0.012)$. Women and men were rated similarly in Medical Knowledge, Physical Examination, Procedural Skills, Professionalism, Practice Based Learning, and System Based Practices (Table 1). There were no significant differences in evaluation results according to gender of the faculty (Table 2) (p-interaction $>0.10$, each domain). Both male and female faculty tended to rate female residents higher in the aforementioned categories.

No differences were observed in mean ABIM certifying examination scores between male and female graduates of the training program over the 5 year study period ( $487 \pm 96$ vs $481 \pm 90, p=0.53$ ) (Fig. 1). Correlations between mean resident evaluation ratings and scores on the certifying examination demonstrated the highest correlations between the Medical Knowledge and Patient Care evaluation domains and the test results (Table 3).

Aggregate data on ABIM initial certifying examination in Internal Medicine performance for first time test takers since 1972 demonstrated a notable increase in the proportion of female examinees, from around $7 \%$ in years1972-1976, rising to $45 \%$ in the years $2010-2015$ (Fig. 2). The pass rate of female examinees has increased steadily over time. Pass rates were initially $20 \%$ higher in male versus female examinees and this difference stayed statistically significant until 1986 (4.5\% higher in male; corrected $P$-value $=0.045$ ). Since year 1987 , this difference is no longer statistically significant; ranging from male pass rate 3.6\% higher (year 1992; corrected P-value $=0.26$ ) to female pass rate $2.5 \%$ higher (year 2002; corrected P-value $=0.06)($ Fig. 2) .

\section{Discussion}

In a large, academic Internal Medicine program, women now comprise approximately $40 \%$ of the resident workforce and of the teaching faculty. Our study has two principal findings: 1) female trainees are rated higher in two important aspects of clinical medicine by attending physicians in our institution, regardless of attending gender and 2) no significant difference is present in first time certifying examination pass rates between female and male trainees, either nationally or within the institution studied herein.

Despite the increase in women in medicine, the number of women in some subspecialties and in higher level academic positions continue to be sparse [10, 12]. Defining the reasons for this lack of parity, and the timeframe where attrition occurs is challenging. We evaluated one institution's evaluations for gender differences to seek answers and spur discussion, and supplemented the data with certifying examination pass rates, both from that institution and nationally.

In our study, we found that female IM trainees were rated as having comparable levels of medical knowledge, and were rated higher in domains reflecting interpersonal skills by attending physicians. This is thought provoking, since it differs from another large study showing no difference in mean ratings by faculty evaluators regardless of faculty gender [5]. Women being rated higher in interpersonal domains, is consistent with previously published reports $[16,17]$. This could be due to 1) a true difference in performance between women and men or (2) evaluator bias to expect women to have better, or men to have worse, skills in the interpersonal domains, or both. Because of the narrow scoring range, and the potential for evaluator implicit bias, we are compelled to exercise caution in overstating any conclusions. Certainly, this area deserves further attention and study.

It should be noted that evaluations analyzed were inpatient rotations, excluding outpatient rotations. As has been well documented in prior literature, the disproportionately higher amount of inpatient experience, as

Table 1 Evaluation scores by domain stratified by gender of resident

\begin{tabular}{llll}
\hline Characteristic & $\begin{array}{l}\text { Female Residents } \\
n=195(40)\end{array}$ & $\begin{array}{l}\text { Male Residents } \\
n=293(60)\end{array}$ \\
\hline Overall & $7.27(1.09)$ & $7.19(1.13)$ & $7.22(0.97)$ \\
Medical Knowledge & $7.21(0.9)$ & & 0.12 \\
Patient Care & & $7.39(1)$ & 0.51 \\
$\quad$ Patient Care, Overall & $7.5(0.94)$ & $7.30(0.91)$ & $7.21(0.89)$ \\
$\quad 7.41(0.86)$ & $7.42(0.87)$ & 0.01 \\
Medical Interviewing & $7.28(0.86)$ & $7.70(0.94)$ & 0.004 \\
Physical Examination & $7.42(0.84)$ & $7.36(0.91)$ & 0.05 \\
Procedural Skills & $7.79(0.89)$ & $7.47(0.96)$ & 0.02 \\
Professionalism & $7.41(0.88)$ & $7.30(0.9)$ & 0.11 \\
Practice Based Learning & $7.61(0.9)$ & 0.001 \\
Interpersonal and Communication Skills & $7.37(0.86)$ & 0.09 \\
System Based Practices & &
\end{tabular}


Table 2 Evaluations of female and male residents stratified by gender of faculty

\begin{tabular}{|c|c|c|c|c|c|c|c|}
\hline \multirow{2}{*}{$\begin{array}{l}\text { Faculty Gender } \\
\text { Resident Gender }\end{array}$} & \multicolumn{3}{|c|}{$\begin{array}{l}\text { Female } \\
n=163 \text { (38) }\end{array}$} & \multicolumn{3}{|c|}{$\begin{array}{l}\text { Male } \\
n=270(62)\end{array}$} & \multirow[t]{2}{*}{ P interaction } \\
\hline & $\begin{array}{l}\text { Female } \\
n=62\end{array}$ & $\begin{array}{l}\text { Male } \\
n=101\end{array}$ & $\overline{p \text {-value }}$ & $\begin{array}{l}\text { Female } \\
n=100\end{array}$ & $\begin{array}{l}\text { Male } \\
n=170\end{array}$ & $\overline{p \text {-value }}$ & \\
\hline Overall & $7.23(0.6)$ & $7.15(0.67)$ & 0.27 & $7.22(0.51)$ & $7.17(0.55)$ & 0.11 & 0.54 \\
\hline Medical Knowledge & $7.18(0.51)$ & $7.18(0.58)$ & 0.82 & $7.17(0.45)$ & $7.21(0.53)$ & 0.44 & 0.24 \\
\hline \multicolumn{8}{|l|}{ Patient Care } \\
\hline Patient Care, Overall & $7.45(0.58)$ & $7.32(0.58)$ & 0.02 & $7.48(0.47)$ & $7.38(0.52)$ & 0.04 & 0.34 \\
\hline Medical Interviewing & $7.40(0.49)$ & $7.28(0.54)$ & 0.009 & $7.37(0.4)$ & $7.28(0.48)$ & 0.02 & 0.29 \\
\hline Physical Examination & $7.27(0.49)$ & $7.17(0.53)$ & 0.06 & $7.25(0.37)$ & $7.19(0.46)$ & 0.11 & 0.12 \\
\hline Procedural Skills & $7.35(0.61)$ & $7.25(0.68)$ & 0.13 & $7.36(0.49)$ & $7.40(0.52)$ & 0.46 & 0.16 \\
\hline Professionalism & $7.73(0.51)$ & $7.63(0.54)$ & 0.05 & $7.77(0.38)$ & $7.70(0.41)$ & 0.04 & 0.08 \\
\hline Practice Based Learning & $7.40(0.51)$ & $7.32(0.53)$ & 0.10 & $7.39(0.42)$ & $7.35(0.46)$ & 0.16 & 0.70 \\
\hline Interpersonal and Communication Skills & $7.60(0.51)$ & $7.47(0.57)$ & 0.01 & $7.59(0.45)$ & $7.45(0.51)$ & 0.001 & 0.62 \\
\hline System Based Practices & $7.34(0.5)$ & $7.25(0.54)$ & 0.07 & $7.34(0.4)$ & $7.30(0.46)$ & 0.20 & 0.22 \\
\hline
\end{tabular}

compared to outpatient experience [18], led us to this decision, but should be factored into its interpretation.

Given the subjectivity of the Likert scale evaluations, we sought corroborative data by obtaining ABIM initial certifying examination scores of the graduating residents. Not only did both the evaluations and the certifying examination scores show no significant difference between women and men, the most powerful correlation between certifying examination scores and a single competency was for Medical Knowledge, supporting the validity of the evaluations.

To further support our data, and to examine whether our data are generalizable to other institutions, we obtained national ABIM certifying examination in IM first attempt pass rates. Pass rates were used instead of score, due to known variability in the scoring and examination

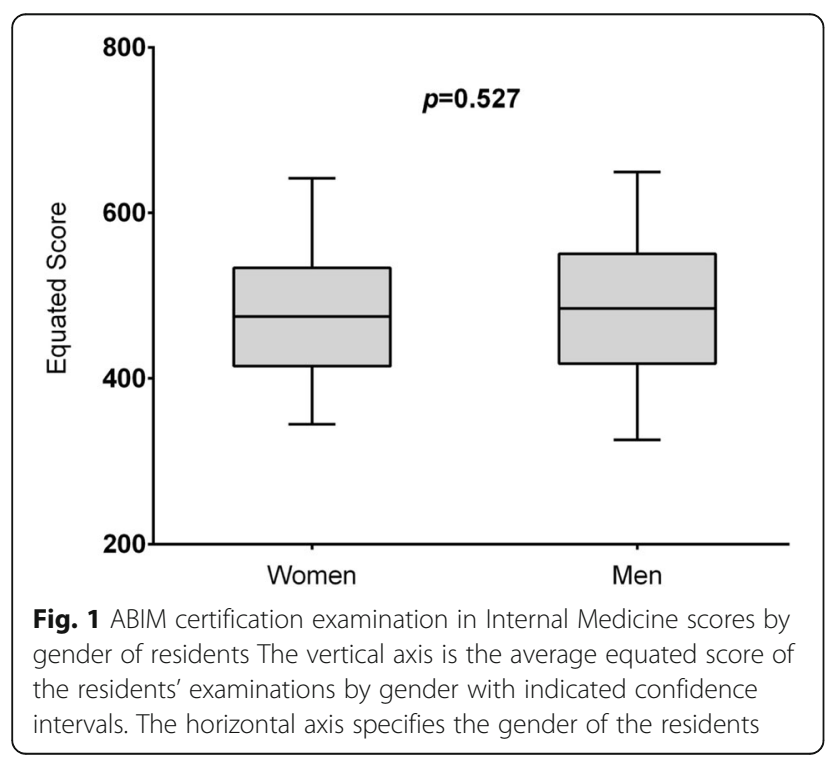

from year to year. In concordance with historical reports [14], men had higher pass rates from the 1970s until the 1980s. However, by 1987, there was no significant difference between women and men's certification examination pass rates. The reason for the discrepancy in pass rates historically is beyond the scope of this study, but prior data supports that neither the method of scoring, nor changes in the types of medical schools or residency programs that the test-takers attended played a factor [13]. This is the first report that confirms that the gender gap in ABIM initial certifying examination pass rate remains closed in the modern era. The consistency of the local and national ABIM data supports the generalizability of our findings.

Despite our findings that suggest that perceived gender-based disparities in medical knowledge and physician competency no longer occur at the resident level,

Table 3 Correlations between individual domain ratings and certifying examination scores

\begin{tabular}{lll}
\hline Domains & \multicolumn{2}{l}{ Overall } \\
\cline { 2 - 3 } & rho & $p$-value \\
\hline Overall & 0.12 & 0.03 \\
Medical Knowledge & 0.25 & $<.0001$ \\
Patient Care & & \\
$\quad$ Patient Care, Overall & 0.12 & 0.001 \\
$\quad$ Medical Interviewing & 0.12 & 0.003 \\
Physical Examination & 0.12 & 0.003 \\
$\quad$ Procedural Skills & 0.12 & 0.04 \\
Professionalism & 0.14 & 0.01 \\
Practice Based Learning & 0.17 & 0.003 \\
Interpersonal and Communication Skills & 0.08 & 0.17 \\
System Based Practices & 0.17 & 0.003 \\
\hline
\end{tabular}




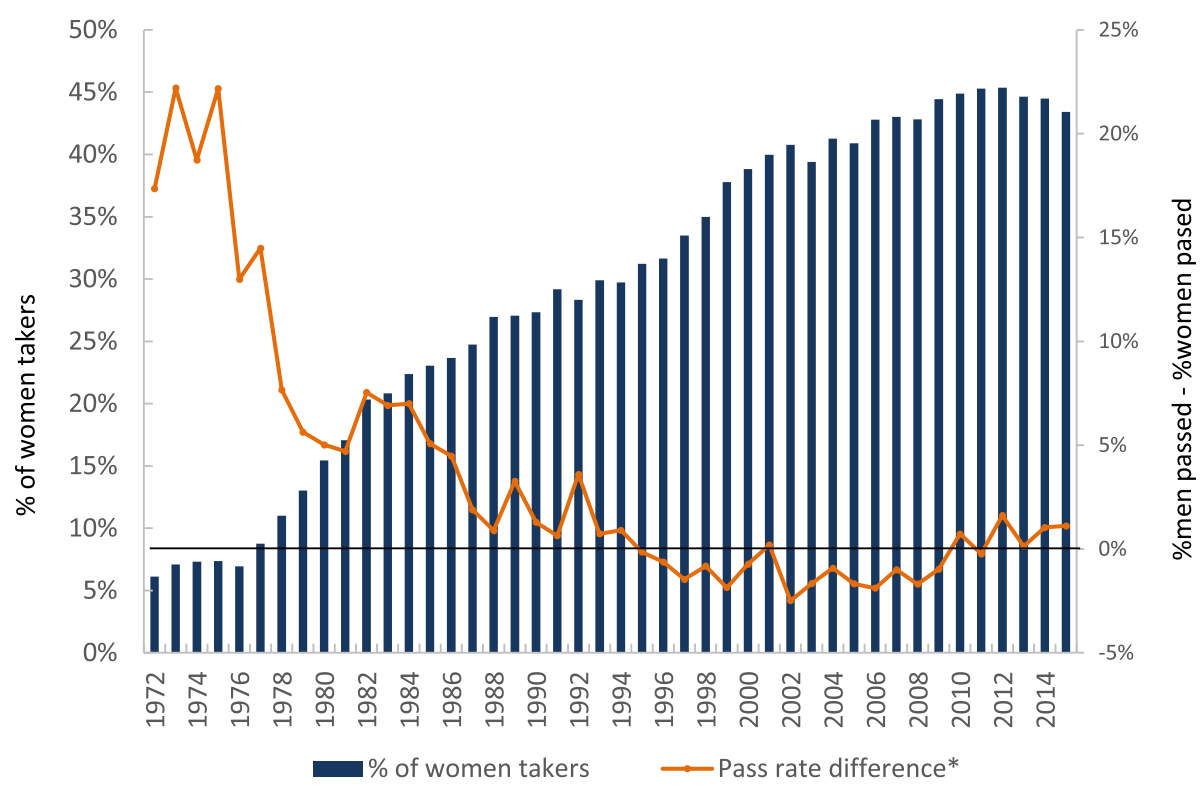

Fig. 2 Gender gap in ABIM certification examination in Internal Medicine first time takers and pass rates This is a line graph with two vertical axes. The primary vertical axis is the percentage of women of the total number of first time takers. The secondary vertical axis is the difference between percent of men passing and percent of women passing for first time takers (i.e. men's pass rate - women's pass rate). The horizontal axis is the year of the certifying exam

at least in our institution, women continue to be underrepresented in certain subspecialty fellowships and higher level academic positions [10,12]. There are many contributing reasons [19-23]. As one example, a recent study found that male residents received more consistent and positive feedback as opposed to female residents [8], suggesting that gender bias is still pervasive in the medical education culture. Despite the widespread movement toward gender equality in the past 50 years [24], increased numbers of women in undergraduate medical education and graduate medical training $[25,26]$, and our data showing equivalent medical knowledge and women having better performance in patient care domains, there remains evidence of gender bias. Currently, close to half of all medical degrees are awarded to women [27]. Efforts to limit gender bias in career development, and to increase the number of female faculty in leadership positions to offer more opportunities for mentorship, coaching and role-modeling should be made to help achieve parity.

Whereas previously, male faculty tended to rate male residents higher [2], our data report demonstrates at one academic institution, there were no significant difference in ratings between female and male faculty. Additionally, women were rated higher in two domains. We speculate that the lack of women in leadership positions and in some subspecialty fellowships are not attributed to a difference in performance or knowledge with respect to gender.

\section{Limitations}

The most important limitation to our data is that it was obtained from a single institution. However, it should be noted that this study has one of the largest number of evaluations, residents and faculty of any study of gender differences in IM graduate medical training to date $[2,3,5,28]$. Moreover, the ratio of female residents to male residents in this study is comparable to national survey data [12].

Another limitation is that our survey instrument, while it was designed using American Board of Internal Medicine and American College of Graduate Medical Education recommendations for assessment, was a semi-quantitative Likert scale whose initial creation lacked traditional testing. While not a validated evaluation tool, the finding that medical knowledge had its highest correlation with ABIM certification exam pass rates suggests that our tool was effective. In addition, our tool can be viewed in Additional file 1 and be compared to evaluation instruments used at other institutions to draw conclusions regarding comparability. Our evaluations also demonstrated range restriction, with the vast majority of responses being between 5 and 8 on the Likert scale. This has been reported previously in the literature, and while a limitation, since commonly found, suggests that our findings may be similar to other institutions [29].

Our study was also limited by the inability to adjust for confounding factors. Learner demographics and data 
such as prior United States Medical Licensing Examination (USMLE) scores and in-training exam scores, as well as the resident evaluations of educators, peer and three-sixty evaluations, were unavailable at time of analysis. Our data was obtained prior to the conversion to milestone ratings by the ACGME in 2014. However, a recent study showed correlation of historical evaluation items to milestone ratings, as well as good correlation of both rating systems to certifying exam scores [30].

\section{Conclusion}

This study is the one of the largest studies comparing resident performance in Internal Medicine between female and male residents. Female residents were rated higher in Medical Interviewing and in Interpersonal and Communication Skills, with similar ratings in the remaining domains. Men and women had similar performance on the initial ABIM certifying examination, both locally and nationally. These data suggest that gender differences in academic leadership positions and certain subspecialties such as cardiology cannot be attributed to gender differences in Internal Medicine resident medical knowledge and physician competency.

\section{Additional file}

Additional file 1: Faculty Evaluation of Resident. (DOCX $17 \mathrm{~kb}$ )

\section{Abbreviations}

ABIM: American Board of Internal Medicine; ACGME: Accreditation Council for Graduate Medical Education; IM: Internal Medicine; PBL: Practice Based Learning and Improvement; SBP: Systems Based Practice; USMLE: United States Medical Licensing Examination; UT: University of Texas

\section{Acknowledgments}

Resident evaluation data was provided by New Innovations Inc. 3540 Forest Lake DriveUniontown, $\mathrm{OH} 44685$, https://www.new-innov.com/pub/, or (330) 899-9954.

\section{Funding}

The authors report no external funding source for this study.

\section{Availability of data and materials}

The datasets generated and/or analyzed during the current study are not publicly available due to the privacy of the residents but are available from the corresponding author on reasonable request

\section{Authors' contributions}

MSS, AK, JDL, LK: Conception and design, data collection, data analysis and interpretation, drafting the article, critical revision of the article and final approval. KS: Data collection, data analysis and interpretation, critical revision of the article and final approval. MS: Data analysis and interpretation, drafting the article, critical revision of the article and final approval. CA, WW: Data collection, data analysis and interpretation, drafting the article, critical revision of the article and final approval. SK, DJ: Data collection, drafting the article, critical revision of the article and final approval.

\section{Ethics approval and consent to participate}

Ethics approval was obtained from the University of Texas Southwestern Medical Center Institutional Review Board. Consent to participate is not applicable to this retrospective study which was deemed exempt by the aforementioned Board.
Consent for publication

Consent to publish is also not applicable.

\section{Competing interests}

David $\mathrm{H}$. Johnson is the former Chair of the ABIM Board of Directors and Weifeng Weng is an employee of the ABIM. Otherwise, the remaining authors have no conflicts of interest to disclose relevant to this manuscript.

\section{Publisher's Note}

Springer Nature remains neutral with regard to jurisdictional claims in published maps and institutional affiliations.

\section{Author details}

${ }^{1}$ Department of Internal Medicine, University of Texas Southwestern Medical Center, 5323 Harry Hines Blvd, Dallas, TX 75390-8830, USA. ²Division of Cardiology, Dallas, USA. ${ }^{3}$ Department of Clinical Sciences, Dallas, USA. ${ }^{4}$ University of Texas Southwestern Medical Center, Dallas, TX, USA. ${ }^{5}$ American Board of Internal Medicine, Philadelphia, PA, USA.

Received: 28 December 2017 Accepted: 26 December 2018 Published online: 07 January 2019

\section{References}

1. Day SC, Norcini JJ, Shea JA, Benson JA Jr. Gender differences in the clinical competence of residents in internal medicine. J Gen Intern Med. 1989;4: 309-12.

2. Rand VE, Hudes ES, Browner WS, Wachter RM, Avins AL. Effect of evaluator and resident gender on the American Board of Internal Medicine evaluation scores. J Gen Intern Med. 1998;13:670-4.

3. Brienza RS, Huot S, Holmboe ES. Influence of gender on the evaluation of internal medicine residents. J Womens Health (2002). 2004;13:77-83.

4. Thackeray EW, Halvorsen AJ, Ficalora RD, Engstler GJ, McDonald FS, Oxentenko AS. The effects of gender and age on evaluation of trainees and faculty in gastroenterology. Am J Gastroenterol. 2012;107:1610-4.

5. Krause ML, Elrashidi MY, Halvorsen AJ, McDonald FS, Oxentenko AS. Impact of pregnancy and gender on internal medicine resident evaluations: a retrospective cohort study. J Gen Intern Med. 2017;32:648-53.

6. Risberg G, Johansson EE, Westman G, Hamberg K. Attitudes toward and experiences of gender issues among physician teachers: a survey study conducted at a university teaching hospital in Sweden. BMC Med Educ. 2008;8:10.

7. Risberg G, Johansson EE, Hamberg K. 'Important... but of low status': male education leaders' views on gender in medicine. Med Educ. 2011;45:613-24.

8. Mueller AS, Jenkins TM, Osborne M, Dayal A, O'Connor DM, Arora VM. Gender differences in attending Physicians' feedback to residents: a qualitative analysis. J Grad Med Educ. 2017:9:577-85.

9. Dayal A, O'Connor DM, Qadri U, Arora VM. Comparison of male vs female resident milestone evaluations by faculty during emergency medicine residency training. JAMA Intern Med. 2017;177:651-7.

10. Carr PL, Gunn C, Raj A, Kaplan S, Freund KM. Recruitment, promotion, and retention of Women in academic medicine: how institutions are addressing gender disparities. Womens Health Issues. 2017;27:374-81.

11. Diamond SJ, Thomas CR Jr, Desai $\mathrm{S}$, et al. Gender differences in publication productivity, academic rank, and career duration among U.S. Academic Gastroenterology Faculty. Acad Med. 2016;91:1158-63.

12. Brotherton SE, Etzel SI. Graduate medical education, 2012-2013. JAMA. 2013; 310:2328-46.

13. Norcini JJ, Fletcher SW, Quimby BB, Shea JA. Performance of women candidates on the American Board of Internal Medicine Certifying Examination, 1973-1982. Ann Intern Med. 1985;102:115-8.

14. Norcini JJ, Kimball HR, Grosso LJ, Day SC, Baranowski RA, Horne MW. Certification in internal medicine: 1989-1992. J Gen Intern Med. 1994;9: $361-5$.

15. Education ACFGM. ACGME program requirements for graduate medical education in internal medicine. 2013.

16. Nicolai J, Demmel R. The impact of gender stereotypes on the evaluation of general practitioners' communication skills: an experimental study using transcripts of physician-patient encounters. Patient Educ Couns. 2007;69: 200-5. 
17. Laidlaw TS, Kaufman DM, MacLeod H, van Zanten S, Simpson D, Wrixon W Relationship of resident characteristics, attitudes, prior training and clinical knowledge to communication skills performance. Med Educ. 2006;40:18-25.

18. Bowen JL, Salerno SM, Chamberlain JK, Eckstrom E, Chen HL, Brandenburg S. Changing habits of practice. Transforming internal medicine residency education in ambulatory settings. J Gen Intern Med. 2005;20:1181-7.

19. Edmunds LD, Ovseiko PV, Shepperd S, et al. Why do women choose or reject careers in academic medicine? A narrative review of empirical evidence. Lancet (London, England). 2016;388:2948-58.

20. Jolly S, Griffith KA, DeCastro R, Stewart A, Ubel P, Jagsi R. Gender differences in time spent on parenting and domestic responsibilities by high-achieving young physician-researchers. Ann Intern Med. 2014;160:344-53.

21. Wahl A. Male managers challenging and reinforcing the male norm in management. NORA Nordic J Women's Stud. 2014;22:131-46.

22. Husu L, Hearn J, Lämsä A-M, Vanhala S. Women, management and leadership - Naiset ja johtajuus; 2011.

23. Wahl A. The impact of gender equality on management and leadership: reflections on change and resistance. In: Liisa Husu JA-MLSV, editor. Leadership through the gender lens. Helsingfors: Hanken School of Economics; 2010. p. 1-20.

24. Valla JM, Williams WM. Increasing achievement and higher-education representation of under-represented groups in science, technology, engineering, and mathematics fields: a review of current K-12 intervention programs. J Women Minorities Sci Eng. 2012;18:21-53.

25. Women in Science. Encyclopedia Brittanica Inc., 2016. https://www. britannica.com/topic/Women-in-Science-2100321. Accessed 5 Feb 2016.

26. (AAMC) AOAMC. The state of women in academic medicine: the pipeline and pathways to leadership 2013-2104. 2013-2014.

27. Ceci SJ, Williams WM. Understanding current causes of women's underrepresentation in science. Proc Natl Acad Sci. 2011;108:3157-62.

28. Holmboe ES, Huot SJ, Brienza RS, Hawkins RE. The association of faculty and residents' gender on faculty evaluations of internal medicine residents in 16 residencies. Acad Med. 2009;84:381-4.

29. Speer AJ, Solomon DJ, Fincher R-ME. Grade inflation in internal medicine clerkships: results of a national survey. Teach Learn Med. 2000;12:112-6.

30. Hauer KE, Vandergrift J, Hess B, et al. Correlations between ratings on the resident annual evaluation summary and the internal medicine milestones and association with ABIM certification examination scores among US internal medicine residents, 2013-2014. JAMA. 2016:316:2253-62.

Ready to submit your research? Choose BMC and benefit from:

- fast, convenient online submission

- thorough peer review by experienced researchers in your field

- rapid publication on acceptance

- support for research data, including large and complex data types

- gold Open Access which fosters wider collaboration and increased citations

- maximum visibility for your research: over $100 \mathrm{M}$ website views per year

At $\mathrm{BMC}$, research is always in progress.

Learn more biomedcentral.com/submissions 